\title{
Managing Workplace Ethics Can Generate Competitive Advantage
}

\author{
J. Michael Alford, The Citadel, USA \\ Mark A. Bebensee, The Citadel, USA
}

\begin{abstract}
The many breaches of ethical conduct and violation of laws by high-profile executives which have been reported for several years have focused attention on the way firms manage business ethics and company values. This paper identifies some of the bottom-line benefits and other benefits of actively managing the business ethics process and recommends practical approaches for developing a program for the management of that process. It is especially important for all enterprises to review their own situations and to become active in this area.
\end{abstract}

\section{INTRODUCTION}

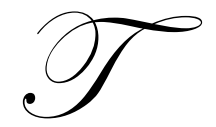

he so-called meltdown of global financial markets over the past few months resulting from largely unregulated risk-taking over the past decade is leading to calls for renewed emphasis on not just establishing reasonable codes of business ethics, but also developing means of discovering violators and enforcing the codes. Examples of financial mismanagement and violations of ethics and laws by the leaders of organizations are found in countries around the world. In the United States, some more recent examples include CitiGroup, Bank of America, General Motors, Chrysler, the Federal Home Mortgage Association, and Goldman Sachs. In Japan, scandals have rocked the nation's top food companies such as Snow Brand Foods and Nippon Ham, as well as nuclear power producers such as Tokyo Electric Power Company (Tepco) and Japan Atomic Power Company. Examples of unethical behavior in Europe include Hafskip shipping line in Iceland, the Elf Aquitaine affair in France, Parmalat SpA in Italy, and Northern Rock in the United Kingdom. These types of problems have caused a number of companies to review their ethics programs. A recent study by Deloitte found that 41 per cent of executives would not voluntarily disclose a "significant incident of corruption" to an anti-bribery agency such as the Serious Fraud Office, and ninety-three per cent would order an internal investigation, but would not routinely report it to a regulator. British firms are not obliged to approach the Serious Fraud Office unless it suspects an act of corruption which involves money laundering or has links to terrorism (TIMES ONLINE, February 2009). ETHICS TODAY reports that 51 percent of British executives would not report suspected violations (ETHICS TODAY, 2009).

These high-profile, high-impact activities and reports tend to mask the fact that most businesses can see a benefit from "managing business ethics," not just establishing and publishing codes of ethics for internal consumption. A recent informal survey of approximately fifty MBA students employed full time in small and medium enterprises which asked questions about the role of formal codes of ethics in their organizations revealed the following:

1. Ethics codes are seen as devices that place the same behavioral expectations on all levels of the organization.

2. Ethics codes enable employees to understand what is expected of them in the workplace.

3. Ethics codes provide a device for enabling employees to communicate to customers and suppliers the expectations of their firm in business dealings.

4. Ethics codes provide a mechanism for handling peer pressure.

5. Ethics codes provide a formal "outside the chain-of-command" way to communicate upwardly in the organization without fear of reprisal. 
These findings provide the basis for exploring some of the benefits of actively managing ethics in the workplace. It should be noted that the phrase "managing company values" is also being used now to denote the process of managing business ethics.

\section{BUSINESS ETHICS}

Discussions of ethics usually involve a concept of moral behavior. It is considered appropriate to separate these two words by using the following approach. "Moral" refers to a set of principles or values that guide behavior. "Ethics," then, is the behavior that conforms to those principles. Placing this in the concept of a business, business ethics is the discipline of developing and practicing business relationships that conform to the moral principles. Sherwin (1983) wrote about what he called "the ethical roots of the business system." Sherwin maintained that to act ethically, a manager must ensure that the owners, employees, and customers all share fairly in the business's gain.

A primary premise of this paper is that all members of the firm, not just managers, have significant roles to play in the active and effective management of ethics in the workplace, and their actions will accrue benefits to the firm and its stakeholders. This is illustrated by survey finding \#1 above, which indicates that codes of ethics place the same behavioral requirements on all members of the organization. The motivations to conduct business in an ethical manner and the positive results will be discussed below.

\section{Codes of Ethics}

Businesses develop formal ethics programs for a variety of reasons. These range from programs designed to comply with the law to programs that provide for both compliance and conducting business on a higher level of trust between the stakeholders. Recent research indicates that some larger firms have developed formal codes of ethics and appointed a Vice President for Ethics in order to avoid the financial penalties imposed for ethics violations. The rationale is that a firm will likely receive a lighter penalty for ethics violations if it has a strong code and an ethics education program in place than if it does not. This approach is merely a tradeoff between the cost of developing an ethics program and the projected cost of possible violations. It neglects some very positive and powerful incentives to actively manage ethics in the workplace.

Whether a code of ethics is formally called a Code of Ethics, a Code of Conduct, a Corporate Code of Ethics, or Values-Based Management, some companies had codes of ethics as early as the beginning of the $20^{\mathrm{th}}$ century (Newberg, 2004). Newberg focuses on Section 406 of the Sarbanes-Oxley Act of 2002 that now requires each public company to disclose annually its code of ethics for the company's CEO and senior financial officers. He maintains that an unexpected result of the code requirement is that the ethical commitments of the codes act as a signal to potential investors, employees, and customers that these are good firms with which to do business.

\section{MANAGING THE ETHICS PROCESS}

Business ethics is now considered a management discipline (McNamara, 1999). Some consider this to have been driven by the social responsibility movement that began in the 60's. Archie Carroll (1979) addressed this with his proposal for a definition of "corporate social responsibility." Carroll held that corporations had four responsibilities to fulfill to society: economic, legal, ethical, and discretionary. The social responsibility movement brought many issues to public view. Two of these were use or misuse of resources and treatment of employees. Pressure was brought on business to use some of the profits derived from the nation's resources to improve society. Such pressures resulted in significant laws, regulations, and the establishment of offices such at the Environmental Protection Agency and the Occupational Safety and Health Administration. The term "stockholders" was changed to the term "stakeholders" by many firms to recognize that employees, customers, suppliers, and communities and countries in which a firm operates are also impacted by the operations of the firm. The stakeholder concept has been extended to include "primary stakeholders," those directly impacted by a proposed action, and "other stakeholders," those for whom there may be some indirect impact. It is common knowledge that environmentalists have included spotted owls, spotted snail darters, and other species of wildlife in their classification of stakeholders in a business action to which they were opposed. The consideration of these broader implications of the firm's activities led to the emergence of business ethics as a management discipline. The formalization of the management of business ethics has taken the path of many other disciplines on the evolutionary path of the "Management" discipline. It has 
been the response to a recognized need, just as the disciplines of strategic management, human resources management, quality management, and other management disciplines have evolved.

\section{Strategic Benefits to Managing the Ethics Process}

A continuing stream of research identifies the strategic benefits to businesses of having actively managed ethics programs. The term "Value-Based Management" is also used to describe what typically has been known as actively managed ethics programs. Some of these will be described below. The research stream goes beyond the benefits reported from the informal survey described in the introduction, but benefits identified in this research stream include all of those observed by the MBA students in their companies.

Amie Devero (2003) cites reports on how firms are using corporate values management for more than just avoiding penalties, fines, lawsuits, and criminal penalties. They are also finding that these programs

- $\quad$ Build employee loyalty, reducing hiring and training costs

- $\quad$ Reduce theft and other anti-company activity

- $\quad$ Drive sales and build customer loyalty

- $\quad$ Create community good will that can lend support for tax advantages and strategic alliances

- $\quad$ Attract quality applicants with minimum investment in recruitment

- Maintain loyal vendor relationships, reducing loss of suppliers and unexpected cost increases

More reports are emerging which support the idea that firms can gain competitive advantage through proper management of business ethics or managing company values, as some call the process. Carter McNamara's (1999) research provides insight into some benefits which expand or are more broadly based than those of Devero. McNamara's benefits include:

- $\quad$ Attention to business ethics has substantially improved society.

- $\quad$ Ethics programs help maintain a moral course in turbulent times.

- $\quad$ Ethics programs are an insurance policy - they help ensure that policies are legal.

- $\quad$ Ethics programs help avoid criminal "acts of omission" and can lower fines.

- $\quad$ Ethics programs help manage values associated with quality management, strategic planning and diversity management.

\section{Topics To Be Covered in Codes of Ethics}

The topics or areas of emphasis in a code will, of course, depend to some degree upon the industry in which a firm predominately operates. The pressure to develop codes of ethics with certain content can be driven by whether the firm has government contracts, what level reporting of financial matters and disclosures is required, and whether a major customer or supplier requires that you develop a code to be sure you are in compliance with their requirements. The Sarbanes-Oxley Law must be used by publicly held firms as one source of guidance. There are industry specific codes which can be used by many firms to guide their efforts. These are recommended for review as the starting point for developing programs. The industry codes are usually more general than the code an individual firm will need. If the firm is a member of an industry group such as The National Association of Realtors, then it has agreed to abide by that group's code. So the firm must ensure that its own code is in agreement with the industry code.

\section{Suggested Outline for Codes of Ethics}

The code of ethics should be a formal statement of the firm's values concerning ethics and social issues. Lockheed Martin (http://www.lockheedmartin.com) has long been recognized as having a thorough and effective code of ethics. Their code evolves from behavior guided by six virtues:

1. Honesty: to be truthful in all our endeavors; to be honest and forthright with one another and with our customers, communities, suppliers, and shareholders.

2. Integrity: to say what we mean, to deliver what we promise, and to stand for what is right. 
3. Respect: to treat one another with dignity and fairness, appreciating the diversity of our workforce and the uniqueness of each employee.

4. Trust: to build confidence through teamwork and open, candid communication.

5. Responsibility: to speak up - without fear of retribution - and report concerns in the workplace, including violations of laws, regulations, and company policies, and seek clarification and guidance whenever there is doubt.

6. Citizenship: to obey all laws of the countries in which we do business and to do our part to make the communities in which we live and work better.

One fairly inclusive outline is presented below. This outline came from the work of two MBA students who developed a code of ethics in the Spring of 2003 for their employer. The firm had rapidly grown from a small firm with about 80 employees to 600 employees. They felt that the rapid expansion had created conditions which called for the formalization of company business values. The effort was welcomed by the management, reviewed by the Corporate Attorney, and subsequently implemented in the company.

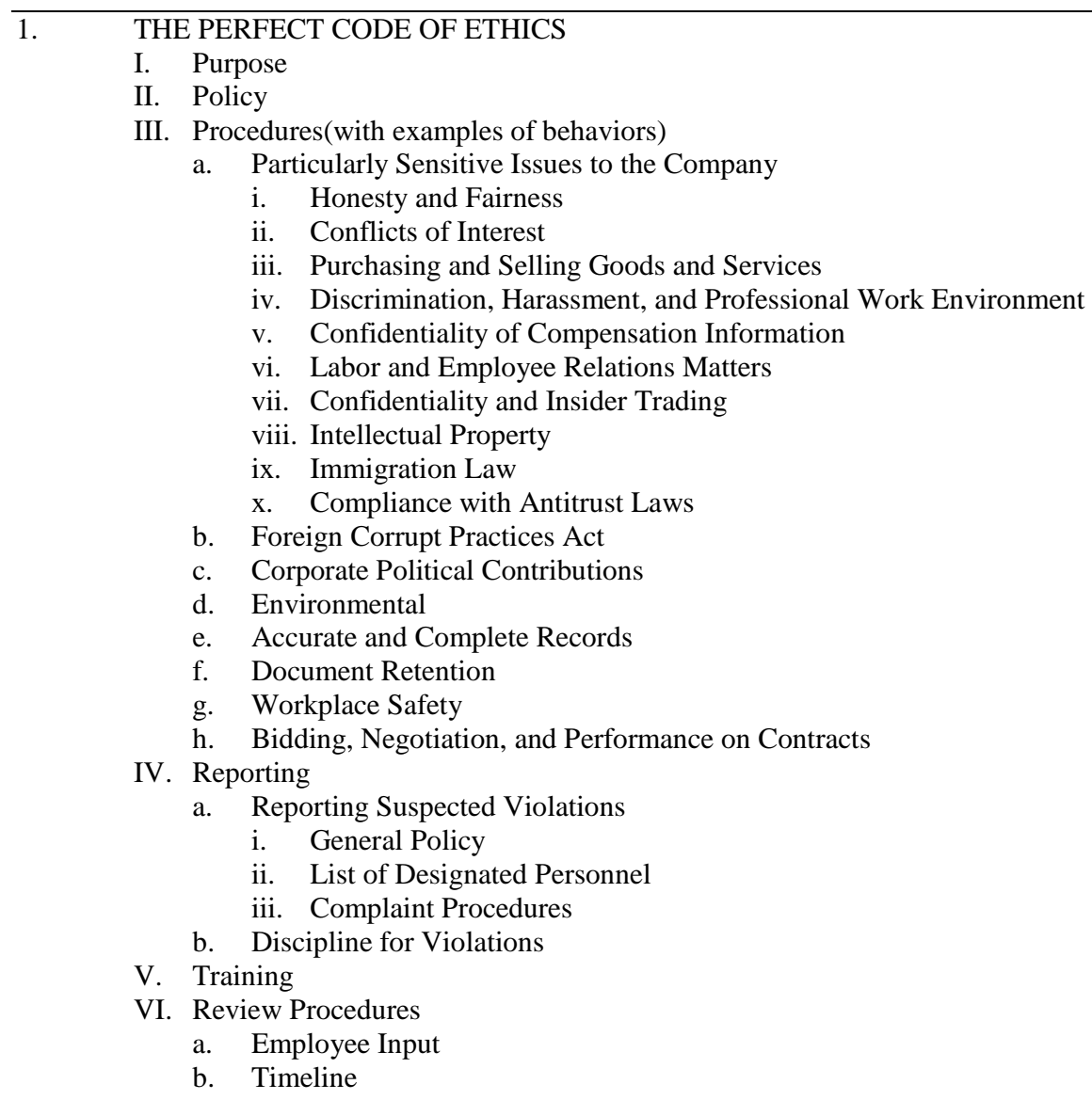

In this company, the ethics program is now a part of each employee's new employee orientation packet and program. Management discusses the importance of ethical behavior at the company and their intolerance of unethical or criminal behavior. Training courses are administered to employees yearly, often through an online training program, which give examples of situations and asks "What would you do?" multiple-choice questions. All employees are required to take this training.

The code of ethics and the training program will be reviewed annually to incorporate any new issues that may have become important to the company in the previous year. More frequent revisions are allowed if new laws are passed, if the company takes on a new type of work, or if the company shifts its focus. A committee was formed with the responsibility of enforcing the code of ethics, guiding employees on the correct course of action to take in questionable situations, and answering employees' questions in about the code. Names and phone numbers of these committee members are provided to all employees. 
The code of ethics outlined above will be more than adequate for most small and medium enterprises. It is provided as a guideline for firms to use in developing codes, whether this is done in-house or by an outside agency. Approaches to developing codes are presented below.

\section{Developing Programs for Managing Business Ethics}

There are two basic approaches to developing formal ethics or values management programs. First is the "do-it-yourself" method. The second is to hire a consultant to help develop the program. A potential third approach, one not often used by businesses, is to approach a local college or university to see if students could undertake such a project under the supervision of a faculty member.

For the small and medium enterprises, there are some obvious advantages and disadvantages to developing programs for the effective management of business ethics and company values. Some potential disadvantages are a lack of staff to dedicate to such efforts, lack of money for additional formal programs, and lack of time because of the press of day-to-day business coupled with a lack of knowledge of the process. Several small business owners have informed the authors that having a formal code of conduct or ethics and actively managing it was high on the original list of items in the startup phase of the business. However, the urgency of running the business caused the ethics programs to slip lower and lower on the list of priorities. Some small business owners feel that because of their short communications chains and fewer people, it should not be necessary to formalize ethics and values programs. It is evident from the informal survey of the MBA students and the research mentioned above that formal programs are seen to provide benefits that add to the bottom line.

One clear advantage for the smaller firms is the fact that there are fewer people both inside and outside the company with which to deal, so the lines of communication are shorter; therefore, it should take less time and effort to formalize programs than would be required in a large organization. Employees can be easily involved in the development of programs. Additionally, these advantages should also facilitate the continuing education and monitoring of programs.

In developing codes and managing ethics in the workplace, there are some steps that should be followed whether a firm does its own development or uses the help of consultants. These steps are:

1. Recognize the need for a formal ethics or values management program.

2. Ask the employees what should be included.

3. Decide whether to develop the program in-house, hire a consultant, or ask a college or university for support. Assign an in-house person the accountability for the program, even if a consultant is hired.

4. Establish a timetable for the development of each segment of the program. These segments include identifying areas to be covered, drafting each area and obtaining feedback, finalizing the written project, determining the methods of education and training for the process of implementing the code, determining whether training and monitoring of the training will be done in house or by an independent party, establishing methods for anonymous of reporting violations and concerns, developing a process for prompt follow-up and reporting of complaints or reports, and establishing dates for program reviews and updates.

5. Establish dates for review and update of the program.

The leadership of the firm should always be visible during the development, implementation, and ongoing reviews of the process.

\section{WHY DEVELOP AND MANAGE BUSNESS ETHICS?}

The development and management of business ethics programs have been shown to provide bottom-line benefits, reduce likelihood of violations, and improve the image of the firm in the business community and the social community. The development and implementation of programs and processes to actively manage company business ethics and values should be looked upon as an investment that will enhance the profitability and the image of the firm. This paper was written in an effort to raise the awareness of the business and social benefits which can be gained by the development of programs for active management of business ethics and company values. Some of 
these benefits were delineated, and a proposed outline for a program to manage business ethics was presented, along with some suggested approaches to developing a program.

There are many excellent websites developed and maintained by leading universities with strong educational and training programs in ethics, as well as books and seminars that can provide guidance to leaders who wish to investigate the benefits of and methods for developing such programs. It is recommended that a member of the firm become familiar with the processes, even if a consultant is hired. It would be overwhelming to list all of the websites, and many of them are excellent; so it is recommended that a web search be initiated by using the key words "Codes of Business Ethics."

\section{CONCLUSION}

There is a general air of mistrust of business by the public. True, the large firms and their leaders have received the media attention to ethical lapses and violations of law. However, the small and medium enterprises are also victims of this era of mistrust. It is important that these firms act to improve their pubic image through actively and publicly managing business ethics. Building the much-needed bridges of trust between the business, its suppliers, its customers, and the community at large will also provide business benefits. The involvement of employees in the process is critical to a program's success. Remember, they are the people who are close to most problems and who have the most to gain by having clear and acceptable codes of behavior to guide their business relationships both within and outside the company.

\section{REFERENCES}

1. Carroll, Archie B., "A Three-Dimensional Conceptual Model of Corporate Devero, Amie, "CORPORATE VALUES Aren't Just Wall Posters - They're Strategic Tools, Annual Editions, Business Ethics, 04/05, pp. 19-21, 2004.

2. $\quad$ ETHICS TODAY, "Current Ethics Concerns," 4/21/09.

3. McNamara, Carter, Complete Guide to Ethics Management: An Ethics Toolkit forManagers, 1999. See website: http://www.managementhelp.org/ethics.

4. Newberg, Joshua A., "Corporate Ethics Codes as Competitive Advantage,"Research@ Smith, Smith School of Business, University of Maryland, Spring 2004, Volume 4, Number 3, p. 2.

5. TIMES ONLINE, "Companies still not owning up to corruption," February 4, 2009. 